Article

\title{
Key Drivers behind the Adoption of Electric Vehicle in Korea: An Analysis of the Revealed Preferences
}

\author{
Eunsung Kim ${ }^{1, *}$ and Eunnyeong Heo ${ }^{2}$ \\ 1 Technology, Management, and Policy Program, College of Engineering, Seoul National University, \\ Seoul 08826, Korea \\ 2 Department of Energy System Engineering, College of Engineering, Seoul National University, \\ Seoul 08826, Korea; heoe@snu.ac.kr \\ * Correspondence: eunsungk@snu.ac.kr
}

Received: 2 October 2019; Accepted: 26 November 2019; Published: 2 December 2019

check for updates

\begin{abstract}
Electrification of passenger cars is one of the most popular ways to decarbonize the transportation sector and to reduce local air pollutants. Many researches have tried to examine what will be the driving factors to achieve the widespread adoption of electric vehicles (EVs). In this study, we analyzed the factors for EV adoption with the data of revealed preference from 2013 to 2017 in Korea. Analyses showed that the driving range of EVs and financial incentives have a positive impact on EV deployment. Also, the driving range is found to be the most critical factor explaining the market growth of EVs. The results suggest that technical improvement increases the value of EVs and in turn raises the probability of consumers' decision to purchase EVs. Financial incentive as well can encourage consumers to buy EVs, however, is not strong enough to create transitions from internal combustion engine vehicles (ICEVs) to EVs.
\end{abstract}

Keywords: electric vehicle adoption; driving range; financial incentive; charging infrastructures; technology adoption; technology policy

\section{Introduction}

The electric vehicle (Electric vehicles (EVs) refers to PHEVs (Plug-in Hybrid Electric Vehicles) and BEVs (Battery Electric Vehicles), excluding HEVs (Hybrid Electric Vehicles) in this study) (EV) market in the Republic of Korea has formed somewhat later than those in the most developed countries, but even so, the domestic market size is increasing at a rapid pace (Figure 1). Especially in 2017, the annual sales of EV increased twofold compared to the figures in 2016, with over 13,800 vehicles sold. Experts who stated that the announcement of the Ministry of Environment (MOE) would reduce the EV purchase subsidies in 2018 compared to 2017 have encouraged consumers who wanted to benefit more from the subsidy to buy the EVs ahead of schedule, and in turn, led to the surge of EV demand in 2017 [1]. Concerns about the possibility of pouring cold water on the growth of the EV market were raised. As Korean EV market was still in the early stages of the market development, it seemed that it was a bad decision for government to cut subsidies. However, this outlook has been overshadowed with a total of 11,866 EVs sold only in the first half of 2018, close to the total number of EVs sold in 2017, and many foresee the EV sales volume in 2018 as over 20,000 vehicles. It means that the market has responded unexpectedly to the curtailment despite many studies having already pointed out that purchasing subsidies is one of the most critical factors of EV adoption [2-8]. 


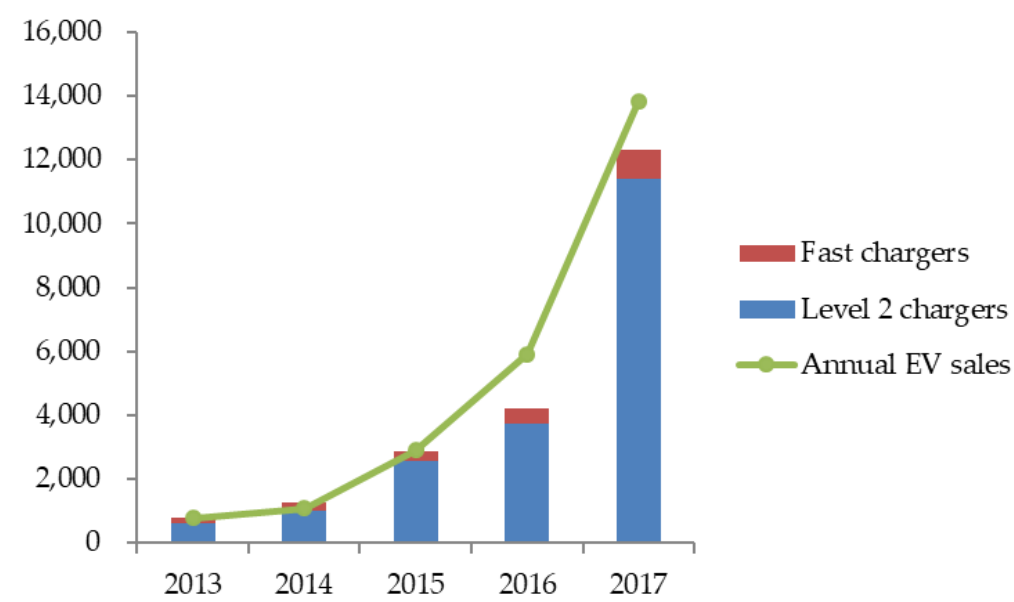

Figure 1. Newly installed charging stations (charging service providers (CSP)' chargers excluded) (Source: Local governments, Ministry of Environment, Korea Environment Corporation).

EVs need charging stations to fill up their batteries. However, the behavior of the EV owners on 'refilling' must be significantly different from that of the international combustion engine vehicle (ICEV) owners since the current technology levels of charging an EV still requires $30 \mathrm{~min}$ or several hours to reach a full charge. At the early stages of EV market formation, considerable uncertainty surrounding the market circumstances has made private operators reluctant to enter the EV charging market. Accordingly, there is a growing demand from the automobile industry, the media, and academia asking government to expand the charging infrastructure. Charging infrastructures can positively affect the diffusion of the EV through the indirect network effect. The increase of EVs could raise the profitability of charging station operators, and in turn, contribute to the growth of the number of charging stations. The proliferation of the charging stations, in turn, raises the utility of EV owners and ultimately boosts the sales of EVs. Therefore, there is a positive feedback loop between EVs and its charging infrastructures. For this reason, a lot of debates have occurred among stakeholders about whether the government should increase the number of EVs by granting a purchase subsidy first or expand the charging infrastructures first.

However, could the adoption of EVs be increased dramatically if there are sufficient charging infrastructures? As mentioned above, although the subsidy was reduced in 2018 compared to 2017, the sales volume of the EV increased by nearly double. It means that the decrease in the subsidy did not decrease the annual sales of EVs. Also, if you look at the actual data (Figure 1), you can find 19,304 Level 2 chargers (Generally, Level 2 charging is known as 'slow charging' in Korea but in this study, we have labeled slow charging as Level 2 charging to avoid any confusion) (private and public). In this study, the private charger means not-freely-accessible chargers which are not registered in the Ministry of Environment Electric Vehicle Charging Stations website [9], a comprehensive system providing the location of all public charging stations in Korea. Public chargers can be searched for on the website and are publicly accessible chargers. To avoid any confusion with the private charger, the chargers installed and operated by private entities are referred to as charging service providers (CSP) chargers, whereas chargers installed by the government and public organizations are referred to as government and public organizations (GPO) chargers)) installed by the local governments through the Korea Environment Corporation by 2017, and a total of 21,914 combined with the public fast chargers installed by the Ministry of Environment and other public institutions. The cumulative number of EVs distributed until 2017 is 25,593 . Therefore, it would seem that the charging infrastructures are not actually in short supply.

The Korean government is aiming to boost the EV market share of new car sales to $6.3 \%$ by 2025 . To achieve this goal, it is imperative to analyze the factors that determine EV adoption with actual data, and the results of this study can provide policy implications to other countries where the EV market 
has not yet formed. Therefore, this study aims to analyze the determinants of the EV adoption based on actual data from 2013, the year of the EV adoption policy implemented to the public in Korea.

Contributions of this paper are as follows. Firstly, the method we used is one of the paper's main strengths. We estimated the results using the negative binomial regression, rather than Poisson, to overcome the overdispersion and cross-sectional heterogeneity of the data. Moreover, we utilized the incident rate ratio (IRR) to compare how certain factors have a greater influence on the sales of EVs than any others. As IRR has multiplicative characteristics, it gives us an advantage in comparing the explanatory power among the independent variables intuitively.

Secondly, we want to highlight how significant it is to target Korea as the scope of analysis. This is due to the fact that the vehicle markets are remarkably different depending on the culture and characteristics of each country. For example, the graph below (Figure 2) shows the light-duty vehicle (LDV) share by vehicle size segment and fuel consumption in 2017 [10]. It is clear that Korea has the highest 'Large car' share among those countries despite being affected by the highest population density among OECD countries (approximately 530 people per square kilometer in 2018 [11]), followed by Netherlands (approx. 508 people per sq. km). It would be plausible to assume that small and compact cars would be preferred in such overcrowded circumstances but surprisingly that is not the case, at least in Korea. Rather, the small car share of Korea is similar to that of Australia, in which the population density is only 3 people per square kilometer. An interesting fact that can be taken from the graph below is that the large car share is exceptionally high while the large SUV / pick-up share is extremely low in Korea. If large-sized cars are more advantageous in Korea than small cars, then the large SUV/pick-up share should be relatively close to the large car share. Moreover, the small car share is higher while the large car and large SUV/pick-up share is lower in the countries of advanced economies with gasoline prices above USD 1 per liter than the countries of advanced economies with gasoline prices below USD 1 per liter (the third and fourth bars from the right in Figure 2). Although the gasoline price in 2017 was above USD 1 per liter (1491 KRW, that is, 1.3 USD) (Table 1), the vehicle market conditions in Korea are relatively different from that in the countries of advanced economies with gasoline prices above USD 1 per liter. Putting these together, it can be noted that Korean consumers consider cars as a showcase of their social standing or luxury goods and the graph below indicates this aspect of the Korean consumers' preference for the large sedan. There was no EV in the large car segment from 2013 to 2017 in Korea, at the early introduction of EV. Therefore, the combination of these characteristics of Korean consumers and the initial situation of the Korean EV market forms a unique circumstance. Thus, it is clear that the analysis of Korea can draw its own significance.

Table 1. Exchange rate and gasoline price in Korea (period average) [12,13].

\begin{tabular}{ccccccc}
\hline & $\mathbf{2 0 1 3}$ & $\mathbf{2 0 1 4}$ & $\mathbf{2 0 1 5}$ & $\mathbf{2 0 1 6}$ & $\mathbf{2 0 1 7}$ & $\mathbf{2 0 1 8}$ \\
\hline $\begin{array}{c}\text { Exchange rate } \\
\text { (KRW per USD) } \\
\begin{array}{c}\text { Gasoline price } \\
\text { (KRW per liter) }\end{array}\end{array}$ & 1094.85 & 1052.96 & 1131.16 & 1160.43 & 1130.42 & 1100.50 \\
\hline
\end{tabular}

Last but not least, we would like to clarify that this study conducted the analysis with the actual sales data, as known as the revealed preference. As the EV market is an emerging market, then the amount of publicly available data is somewhat lacking. For this reason, the existing works of literature mostly carried out the survey regarding the specific circumstances for which consumers would buy EVs [14-16], or who would buy EVs $[17,18]$. However, there exists the "attitude-action gap" of consumers in an emerging market, especially the market for green innovation products $[19,20]$. Even if consumers have a tendency to purchase eco-friendly products based on environmental protection or economic feasibility, there is a large gap between the "intent to purchase" and the actual purchase. For instance, according to a recent survey of 500 adult men and women in Korea, $94 \%$ of the respondents responded yes when they were asked whether they are willing to buy an EV in the 
future [21]. Meanwhile, the share of EVs in the total registered non-commercial vehicles as of 2018 in Korea only accounts for $0.3 \%$ [22]. This huge gap between the two figures is one example of the "attitude-action gap". Therefore, when examining the key drivers of EV adoption, it is more appropriate to use the revealed preference, that is the actual sales data, not the stated preferences. Although the observations do not represent a significant number, the data we used are the best ones that are thus far publicly available since the EV adoption of the general consumer in Korea started from 2013 and the minimal unit of data from the National Statistical Office is in municipalities. Moreover, it is worthwhile to review the key drivers of the EV adoption in Korea in the early stages of the introduction of EVs.

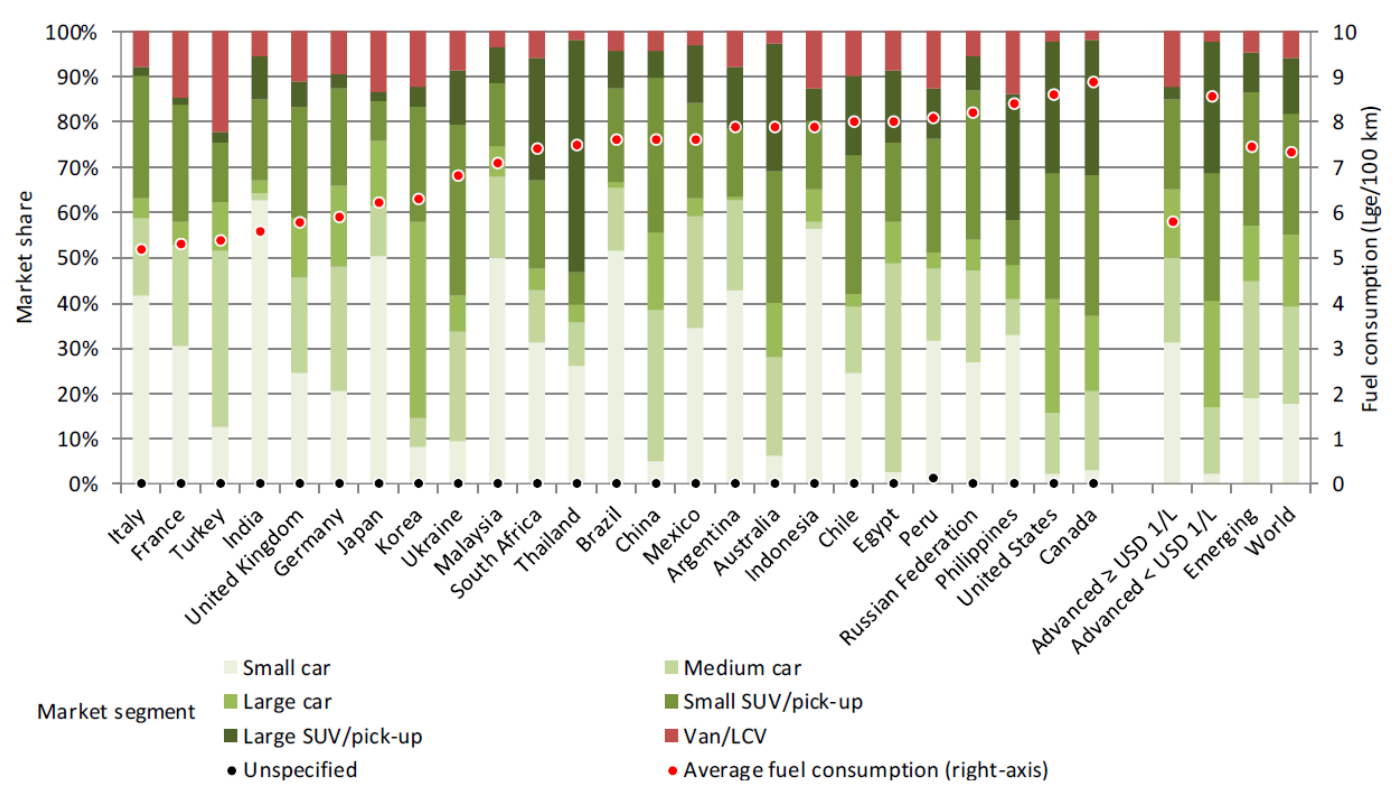

Figure 2. The light-duty vehicle (LDV) share by vehicle size segment and fuel consumption in 2017 [10]. (The country-groups and world only include the country listed in the graph. LCV = light-commercial vehicle. Advanced $<$ USD 1/L = advanced economies with gasoline prices below USD 1 per litre; Advanced $>$ USD 1/L = advanced economies with gasoline prices above USD 1 per litre. Unspecified is the share of vehicles where there is no data on the size segment and the values are not included in the denominator to calculate market shares. (Source: IEA analysis based on IHS Markit database (IHS Markit, 2018)).

\section{Literature Review}

Due to the nature of this emerging market, there is an obvious limit to the data regarding the EV that can be obtained. Therefore, the majority of previous studies have analyzed the stated preference of consumers through surveys, mainly for countries in which the EVs are relatively more deployed than others. For example, US [14,23-26], China [8,16,27], Norway [28], Sweden [4,29], Netherlands [30], UK [31], Germany [17], and Spain [15] were studied and some of the research were conducted from a global perspective [18,32]. In the eco-car market, the consumer's "attitude-action gap" is significant [19,20], so the research based on the stated preferences have limitations in that they are often far from what is actually happening in the actual market [23,33]. Thus, there is a growing need for research based on the revealed preference.

A few studies of the empirical analysis with the revealed preference can be found [33-35]. However, as the characteristics of the automobile market vary from country to country, it is more appropriate to analyze one country for a certain period than to compare many countries at once. There are few studies that have examined Norway and the United States in accordance with the revealed preferences respectively $[5,36]$. As these two countries are the EV lead markets, the likelihood of obtaining comprehensive data is strong. 
By and large, Korea has not been studied comprehensively for the EV adoption because not that much time has passed since EVs have been sold in earnest and the relevant policies have been implemented. Even so, in terms of research, it is relatively difficult to find any existing studies that analyzed the factors of the adoption of the EV. In recent studies, EV diffusion was reviewed based on the stated preference [37-39].

There is a conjoint analysis that has dealt with the consumers' preferences for EVs and fuel-cell vehicles with regard to their adoption potential [38]. The questionnaire was utilized for a driver group and non-driver group respectively. As a result, both groups showed that the vehicle purchase price was the most crucial factor for vehicle selection, the driver group chose the number of charging stations as the second most important factor, whereas the non-driver group chose the $\mathrm{CO}_{2}$ emission. However, the authors calculated the market share of EVs in 2016 with the results of the analysis to be $13.52 \%$, which is far from the actual value of $0.72 \%$.

In [37], the consumers' perceptions of EV policies were analyzed for the actual EV users residing in Jeju Special Self-governing Province in Korea. Unlike the existing literature on the survey of potential users $[24,40]$, the marginal willingness-to-pay for the charging time reduction was very high, indicating that actual users felt very uncomfortable about charging EVs.

Besides, the actual EV users showed a preference for the operational cost subsidy such as an electricity price discount rather than the purchase subsidy. The relationship between the perceived value of EVs and the actual EV selection also showed similar results [39]. However, in Korea, the charging fee of the fast chargers was free until 2015 whereas that of the Level 2 chargers has been collected, and users have to pay the charging fee from 2016(KRW 313.1/kWh, the fee of the Level 2 charger has remained the same) which means that the EV users' financial burden has increased. Nonetheless, 5914 vehicles, which is more than double that of 2016, were sold compared to the number of EVs sold in 2015 (2907 units). Therefore, the result of [39] might reflect the fact that drivers are not calculating the fuel cost savings correctly or consumer decisions regarding the fuel economy are more heavily influenced by emotion rather than analysis [41,42].

Using the revealed preference data of Korea gives us two main advantages. Firstly, both the amount of the purchase subsidy and that of the vehicle tax exemption for EVs in Korea do not depend on the purchasers' income levels. Therefore, we can examine the effect of financial incentives on EV adoption more clearly than using the data from the country which gives financial incentives depending on the recipient's income level. Secondly, the revealed preference data capture what is actually happening in the market better than the stated preference data because the consumers' willingness to pay does not always match with their actual purchase.

The order of this study is as follows. In Section 3, data and variables are explained, and then models and results are presented in Section 4 . Finally, we suggested the conclusions and implications in Section 5.

\section{Data and Variables}

In this study, we analyze the factors influencing the EV diffusion based on the data of 16 metropolitan municipalities (Currently, there are 17 municipalities in Korea, including Sejong Special Self-Governing City. While Sejong city was launched in July 2012, the statistical data are available as of 2010, so there is no separate data available at present for it. Therefore, the data of Sejong city were integrated into Chungcheongnam-do and we analyzed 16 regions in total) in Korea. Korea's EV diffusion policy focused on a strategy to create an initial market through demonstration projects and public sector-oriented pilot distribution from 2010 to 2012. Since the policy that was implemented to the public started practically from 2013, we decided to set the analysis period from 2013 to 2017.

There are two reasons that the dependent variable is measured by the annual sales of EVs rather than the cumulative number of EVs or the market share of EVs in new car sales, which is frequently used in literature. One is for the technical reasons since this study conducted a panel analysis of 16 local governments in Korea, and we require the total number of automobile sales by region in 
order to calculate the market share of EVs sold, which can barely be obtained. The other is due to the importance of the sales volume data itself. Sales are involved in both the learning effect and the economies of scale of the production sector and the network effect of the consumer sector through the formation of an installed base. Besides, the increase in sales contributes to the development of battery technology, which will play a vital role in the diffusion of EVs through a contribution to profit, so the sales number is used as it is to prevent the loss of information.

In this study, seven variables were finally selected as the explanatory variables that showed a statistically significant influence on EV diffusion in the previous studies (Table 2). Explanatory variables can be grouped, one is the technology-push factors, and the other is the demand-pull factors. In addition to the variables discussed in this study, other factors might affect EV diffusion. However, it is limited to the above seven variables by the fact that including a lot of less critical variables could dilute the results. The descriptive statistics of explanatory variables are presented in Appendix A (Table A1).

Table 2. Explanatory variables and literatures.

\begin{tabular}{ccc}
\hline & Variables & Literatures \\
\hline \multirow{2}{*}{ Technology-push factors: } & Range & {$[3,6,14,15,18,24,25,29,31,40,43,44]$} \\
& Diversity & {$[18,31,40,43,45]$} \\
& Price & {$[8,14,15,18,24,29,44]$} \\
\hline & Income & {$[5-8]$} \\
Demand-pull factors: & Purchase subsidy and tax reduction & {$[2-8]$} \\
& Charging infrastructure & {$[3-6,14,15,18,24,29,40,43,44]$} \\
& Fuel-cost saving & {$[4,6-8,14,17,18,24,31,44]$,} \\
\hline
\end{tabular}

Technology-push factors are the attributes of the electric car itself, the range with a full charge, the number of models that can be selected, and the price difference between the same-class internal combustion engine vehicles (ICEVs) and EVs. The development of battery technology is one of the most critical factors in the diffusion of EVs. Battery density is the most representative variable of the battery performance. As the battery density increases, the driving range increases and the battery price per unit power decreases at the same time. Consumers can recognize the innovation of battery technologies by the increase in the driving range and the reduced price of EVs so that the range and price difference with ICEVs are selected as the explanatory variables. The average of the driving range of each EV model available in that year is used as the variable, and each driving range is based on the distance traveled at room temperature $\left(20-30^{\circ} \mathrm{C}\right)$ with a full charge. To calculate the price difference, the price of the corresponding gasoline vehicle to each EV model available in that year is subtracted from that of the $\mathrm{EV}$, and the differences are averaged (diesel car in the case of no gasoline car).

Moreover, it is reasonable to assume that the more various products are given, the more likely the consumers will find a satisfactory car. In [45], the authors divided the Canadian consumers into groups according to the vehicle body type for the next vehicle (economy, intermediate-size sedan, full-size sedan, luxury sedan, minivan/crossover, sport utility vehicle (SUV), and pickup truck), and unlike the HEVs, each group showed different preferences for the PHEVs and BEVs. We expect that it would be easier for consumers to find the cars that meet their needs if the body type, including the design of EVs, is provided in various ways.

Demand-pull factors are explanatory variables that indicate the consumers' purchasing conditions. The first one is the local gross income per capita. The higher the consumer's income is, the higher the probability of purchasing an EV is, considering the relatively high price of EVs.

Subsidies and tax exemption are also critical for EV adoption. Due to the low price competitiveness of EVs compared to ICEVs, governments provide the subsidy and the tax benefit to EVs, thus making it cost-competitive. Subsidies consist of central government expenditure and that of local governments. Although central government expenditure is uniformly supported nationwide, the level of local governments' support differs according to each locality, which in turn impacts on the annual sales 
of EVs by region. As of 2017, an EV buyer in Korea will enjoy various tax benefits of 4.6 million KRW (approximately 4066 USD with an exchange rate as of 26 November 2018 (1131 KRW = 1 USD)) including individual consumption tax of KRW 2 million, education tax of KRW 600,000, and an acquisition tax of KRW 2 million, and annual vehicle tax for EVs is KRW 130,000 regardless of the vehicle body type. Tax benefits such as an individual consumption tax occur once at the time of purchase while the exemption of the vehicle tax is an annual benefit. For example, the owner of a standard medium-sized passenger car $(2000 \mathrm{cc})$ with an internal combustion engine is required to pay a vehicle tax of KRW 520,000 per year, but for EV owners, he or she can save KWR 390,000 per year. In this study, the sum of all tax benefits and subsidies is used as an explanatory variable of the subsidy and tax benefits. With regard to the vehicle tax benefit calculation, we assumed that people both have a 5 -year payback period and a $10 \%$ discount rate.

Third, the number of charging stations adjusted to the number of registered EVs was set as the explanatory variable. As mentioned earlier in the introduction, the more chargers that are available, the easier it is to use the EVs so the number of charging stations would have a positive impact on the EV adoption. Since charging service providers have not made their time-series charging stations data available to the public, only the data from local governments and the Ministry of Environment are included here. In Korea's EV support program, in order to prevent the imprudent proliferation of EVs without taking into consideration the charging facilities, it was necessary to examine whether a prospective subsidy recipient can use fixed chargers in the recipients' selection process. For this reason, only the EV purchasers were able to receive the full Level 2 charger installation subsidies from the local governments until 2016, and if they did not want to install it, they had to submit a disclaimer regarding the installation subsidies. People are highly unlikely to spend tens of thousands of dollars on a car defined by emerging technology without a purchase subsidy whose price is nearly double the price of an ICEV. Furthermore, they will not install a Level 2 charger at home with installation costs of several million KRW without a subsidy accompanying it. Therefore, it is plausible to assume that the number of level 2 chargers is determined almost simultaneously with the number of EVs and that means if the number of Level 2 chargers is used as an explanatory variable, then the endogeneity problem will arise.

The problem that is always mentioned in EV diffusion is 'range anxiety,' which means the psychological uneasiness that one could be stranded on the road caused by the shorter range of EVs and by the insufficient charging infrastructure. In addition to the mainly used charging points such as residential buildings or workplaces, if there are plenty of charging stations on the roads, then it will be of great assistance in increasing the EV acceptance of potential customers. Therefore, in this study, the number of public fast chargers installed by the Ministry of Environment was selected as a measure of the charging infrastructure but adjusted by the number of registered EVs in each region because it takes a long time to charge.

The last variable is fuel cost saving. EVs can achieve higher economic benefits over its life through the reduced fuel costs than ICEVs. Therefore, it can be considered that the reduction of the fuel costs can increase consumers' preference for the purchase of EVs, though it is not generally the case in previous studies. In this study, the fuel cost savings were calculated based on the following criteria: (1) the payback period is five years, (2) gasoline price, electricity rates, fuel efficiency, and annual mileage are assumed to be the same as the first year of purchasing the EVs during the payback period, (3) everyone's fast-to-Level 2 ratios of charger usage (on a charge basis) is 3:7, and (4) everyone's discount rate is at the same level. Previous studies have shown that many consumers tend to incorrectly gauge the size of the fuel economy benefits $[33,42,46,47]$, to such an extent that they are unaware of the potential cost savings $[3,8,14]$, and in most cases the fuel cost savings are not the primary attribute governing the vehicle purchase decision [14,25]. Therefore, this study conservatively set the discount rate at $10 \%$ and the payback period at 5 years.

The descriptive statistics of explanatory variables are presented in Appendix A (Table A1). 


\section{Models and Results}

\subsection{Models}

The dependent variable, the number of annual sales of the EVs, is count data. For count data, the Poisson regression or negative binomial regression is mainly used in the analysis [48]. In the Poisson regression, the assumption that the mean and variance are the same should be met. The conditional variance of the annual sales of EVs is large enough compared to the conditional average and is very heterogeneous by region (Table A2). Considering overdispersion and cross-sectional heterogeneity, we adopted the negative binomial regression instead of the Poisson regression.

The models that explain the annual sales of the EVs are as follows:

$$
\begin{aligned}
\text { Sales }_{i, t}= & \beta_{1} \text { Diversity }_{i, t} \\
& +\beta_{2} \text { Range }_{i, t} \\
& +\beta_{3} \text { Price }_{i, t} \\
& +\beta_{4} \text { Income }_{i, t} \\
& +\beta_{5} \text { Subsidy }_{i, t} \\
& +\beta_{6} \text { Chargers }_{i, t} \\
& +\beta_{7} \text { FCSaving }_{i, t}+\alpha_{i} \\
& +\varepsilon_{i, t}
\end{aligned}
$$

$i=1,2, \ldots, 16$ stand for each municipality, $t=2013, \ldots, 2017$ for the year.

In this negative binomial regression model, we can interpret the sale of one EV as an event in which a consumer chooses an EV instead of an ICEV when deciding to purchase a car. Therefore, we set up the model in which the annual sales of the EVs follow the Poison process with an unobservable error parameter introducing heterogeneity in the variance, while the vector of the explanatory variables $(X)$ explains the intensity parameter $(\mu)$.

Sales $_{i, t} \rightarrow \operatorname{NegBin}(\mu ; \sigma)$, that is,

$$
\text { Sales }_{i, t} \rightarrow \operatorname{Poisson}(\mu) \text { with }\left\{\begin{array}{c}
\mu=\bar{\mu} \cdot u=\exp (\beta X) \\
u \rightarrow \Gamma\left(\frac{1}{\sigma} ; \frac{1}{\sigma}\right)
\end{array}\right.
$$

\subsection{Results and Discussion}

The results are shown below (Table 3). It was imperative that we utilized the incident rate ratio (IRR) to compare how certain factors place greater emphasis on the EVs more so than any others. As the IRR is defined by multiplicative characteristics, it presents us with a clear advantage in comparing the explanatory power among the independent variables intuitively. For example, if the IRR of an explanatory variable is 1.5 , then this signifies that a one unit increase in the explanatory variable raises the occurrence probability by 1.5 times.

Table 3. Negative binomial regression results.

\begin{tabular}{cccccccc}
\hline & Diversity & Range & Price & Income & Subsidy & Fast Chargers & Fuel Cost Savings \\
\hline IRR & 0.954 & $1.042^{* * * *}$ & 1.000 & 1.000 & $1.001 * * *$ & 0.729 & $0.996^{*}$ \\
$\begin{array}{c}\text { Standard } \\
\text { error }\end{array}$ & $(0.117)$ & $(0.007)$ & $(0.003)$ & $(0.000)$ & $(0.000)$ & $(0.459)$ & $(0.002)$ \\
\hline
\end{tabular}

*: $p$-value $<0.1,^{* *}: p$-value $<0.05, * * *: p$-value $<0.01$.

Firstly, both the range and subsidy have a positive and robust impact on the annual sales of the EVs, however, the magnitude of the impact is much higher in range than the subsidy. According to the results of this study, the number of EVs sold will increase by approximately 1.04 times, that is, 
$4.2 \%$ when the range is increased by one unit if all else is equal. On the other hand, a one unit increase of the subsidy merely elevates the possibility of the EV being sold at $0.1 \%$.

In fact, the driving range has often been underestimated in the works of literature. Some argued that since the average mileage of the drivers is relatively short, the range of the EVs will not be a severe impediment for the EV diffusion [38]. Additional studies also asserted that the existing BEV models can already cover the vast majority of daily trips [49-51] making it feasible to replace a significant portion of the ICEVs [51] and reduce the gasoline consumption by approximately $60 \%$ with the existing BEVs [49]. Moreover, the range-anxiety is even considered to be a psychological issue, rather than a technical one [46].

However, there seems to be a number of misconceptions regarding the concept of the range of EVs. Since a greater deal of time and effort are required for frequent charging, the longer the range is, the higher the convenience for the consumers. The survey from the EV owners in the US indicates that even though the existing EVs already provide the majority of the respondents' daily trip needs, people still require a greater range, approximately more than three times their daily trip [25]. Therefore, it is not a matter of the daily trip or the local area coverage, but whether the driving range of the EVs becomes closer to that of the ICEVs or not.

Here is where meaningful policy implications can be drawn. Currently, the Ministry of Environment (MOE) is responsible for the diffusion of the EVs in Korea and its main policy instruments are the purchase subsidies, tax benefits, and the expansion of the charging station. These are all demand-pull policies that lower the barriers to the adoption of EVs. On the other hand, R\&D, which is a representative technology-push policy, is administered by the Ministry of Trade, Industry, and Energy but the roadmaps for R\&D regarding EVs technology seem to be declarative goals and even proper statistics of R\&D expenditure cannot be obtained. As we have seen, the demand-pull policies such as purchase subsidies and the charging infrastructure tend to work correctly after technological innovation has taken place so that the current demand-pull-centered policies need to be reconsidered.

Secondly, it can be seen that the public fast chargers of the MOE have a negative impact on the annual sales of the EVs even though it is statistically insignificant. This result seems to be counter-intuitive. Thus, a possibility exists that the Level 2 chargers have been mainly used while the fast chargers have played an auxiliary role. At the time when one has to move his or her car out of the parking lot after $30 \mathrm{~min}$ of fast charging, the Level 2 chargers can provide a great many advantages over the fast chargers to the EV owners who want to charge during the time when the car is parked at home, the workplace, or at your convenience.

One piece of evidence can be found in the survey results of the actual user of EVs and the status of the installation of the charging station. If you look at the statistics (Figure 3), the majority of the GPO chargers are fast chargers while the CSP chargers are mostly Level 2 chargers. According to [1], the EV users in Korea charge their vehicles mainly at GPO stations (31.0\%), home (27.9\%), CSP stations $(24.0 \%)$, and the workplace (15.3\%) (Figure 3). Considering the convenience of charging and the cost of a charger installation, it is reasonable to assume that the in-home chargers are predominantly Level 2 chargers, and the same can be said of the chargers used at work. Together with the fact that the CSP chargers are mostly Level 2 chargers, the effective utilization ratio between the fast and Level 2 chargers of the actual EV owners in Korea is approximately 3:7 at a maximum. Therefore, in such a situation, the fast charger may be used only for charging in an emergency or may have played only a psychological role in reducing the range anxiety. As mentioned in chapter 3 , the charging service providers have not made their time-series charging stations data available to the public so unfortunately, we have been unable to use those data. 


\begin{tabular}{c|r|r|r}
\hline $\begin{array}{c}\text { Public chargers } \\
\text { operated by }\end{array}$ & $\begin{array}{c}\text { Fast } \\
\text { chargers } \\
(\%)\end{array}$ & $\begin{array}{c}\text { Level 2 } \\
\text { chargers } \\
(\%)\end{array}$ & $\begin{array}{c}\text { Total } \\
(\%)\end{array}$ \\
\hline \hline $\begin{array}{c}\text { Government and } \\
\text { public organization } \\
\text { (GPO) }\end{array}$ & 2,696 & 190 & 2,886 \\
\cline { 2 - 4 } & $(93.4)$ & $(6.6)$ & $(100.0)$ \\
\hline $\begin{array}{c}\text { Charging service } \\
\text { providers } \\
\text { (CSP) }\end{array}$ & 608 & 3,521 & 4,129 \\
\cline { 2 - 4 } & $(14.7)$ & $(85.3)$ & $(100.0)$ \\
\hline \hline & 3,304 & 3,711 & 7,015 \\
\cline { 2 - 4 } Total & $(47.1)$ & $(52.9)$ & $(100.0)$ \\
\hline
\end{tabular}

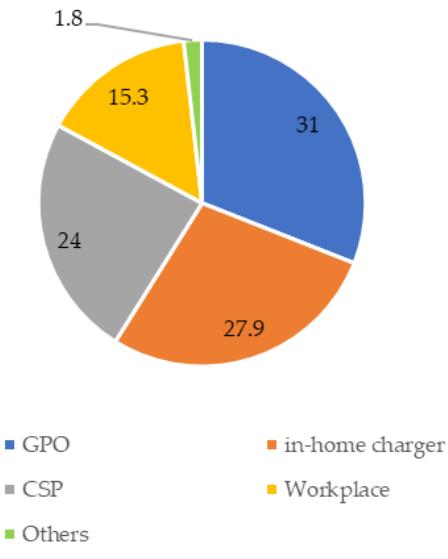

Figure 3. The number of public chargers and the ratio of charging by EV owners (Source: [1-9]). Based on the total ports number in October 2018.

Diversity displays no apparent relationship in the models even though the number of selectable models has almost tripled over the past 5 years. This is probably due to the fact that the Korean consumers generally prefer large sedans, as already mentioned in the introduction, whereas the only available EVs during the analysis period were small compact cars so that the number of selectable models itself did not have much effect to the sales of EVs. The authors expect that it will be more insightful if the explanatory variable that represents the existence of large sedans would be included in any future research. Furthermore, the result also does not indicate whether the price difference between the EVs and ICEVs have a significant negative impact on the EV diffusion. It seems that as Korean governments have provided a large amount of economic support for the EV purchase to compensate for the relatively high price of the EVs, those incentives have blurred the negative impact of the price difference.

Finally, the result of the fuel cost savings is of great interest. According to the results, each unit increase in the fuel cost saving lowers $0.4 \%$ of the sales of EVs. This statistically significant result is counter-intuitive and any supporting reasons are likely to be found in previous literature. Numerous studies have shown that people tend to incorrectly estimate the size of the fuel economy benefits $[5,33,41,42,52]$ and hardly concern themselves with the potential cost savings $[3,8,14]$. Besides, when making a vehicle purchase decision, they do not seriously consider the fuel cost savings in the vehicle purchase decision $[11,12,24]$ or even misconceive that the high fuel economy can only be achieved by compromising the performance and safety [20]. When you look at the Table below (Table 4), although using an EV has been clearly more economically beneficial than when using a gasoline vehicle and the fuel cost saving has been decreased during the analysis period, the annual sales of the EVs neither replaced the ICEVs nor decreased as the fuel cost saving decreased from 2013 to 2016. These data also support the findings in previous studies that people display seemingly irrational behavior regarding fuel cost savings. 
Table 4. Potential economic benefit of EV owners.

\begin{tabular}{ccccc}
\hline & $\begin{array}{c}\text { Average Price } \\
\text { Difference with } \\
\text { Gasoline Vehicles }\end{array}$ & $\begin{array}{c}\text { Subsidies } \\
\text { and Tax Exemption } \\
\text { (10 Thousand KRW) }\end{array}$ & $\begin{array}{c}\text { Fuel Cost Saving } \\
\text { (Fast: Level 2 = 3:7) }\end{array}$ & $\begin{array}{c}\text { Potential } \\
\text { Economic Benefit }\end{array}$ \\
\hline 2013 & 2501.3 & 2446.8 & 491.8 & 437.3 \\
2014 & 2415.2 & 2343.7 & 471.8 & 400.4 \\
2015 & 2351.5 & 2390.6 & 354.0 & 393.1 \\
2016 & 2174.9 & 2385.6 & 244.5 & 455.3 \\
2017 & 2274.4 & 2611.2 & 437.1 & 773.9 \\
\hline Average & 2317.4 & 2435.6 & 399.8 & 518.0 \\
\hline
\end{tabular}

\section{Conclusions and Policy Implications}

The electrification of the transportation sector is vital to abate severe air pollution in Korea, as well as to make a breakthrough in the climate change issue, the common goal of the world. As EVs emit no local pollutants and are up to three times as energy-efficient as ICEVs [53], it is expected that diffusion of EVs would alleviate many of environmental burdens. The first step for accelerating the replacement of the ICEVs with EVs would be to discover what encourages people to adopt the EVs. For this reason, we analyzed the relationship between the EVs and the explanatory variables using the actual sales data of the EVs in Korea from 2013 to 2017.

The result confirms that the driving range and financial incentives such as subsidies and tax exemption have a positive impact on the EV diffusion, and especially, the driving range is the most significant variable explaining the adoption of the EVs. Although existing EV models can cover most of the daily trips [49-51], it does not mean that most of the existing ICEVs will be replaced with the EVs right away. It is not a matter of subsidy or infrastructure readiness, but a matter for the competitiveness of the EVs compared to the ICEVs. Even with an in-home charger, the experiences that the owners have with regard to the EVs are completely different for daily charging, charging twice a week, and charging twice a month to cover the daily trip. In order to be a dominant design, the EVs must provide more value than the ICEVs to the consumers. When the value provided by the EVs is greater than the value that the consumers expect for traditional ICEVs, or the new value from the EVs is large enough to offset the awkwardness and reliability issues facing emerging technology, the replacement from the ICEVs to EVs in the mainstream vehicle market will occur. In this study, we could not find a clear relationship between the EV diffusion and the fast charging infrastructures. This may be because the public fast chargers performed only an auxiliary role in such a long-distance journey or emergency because the primary source of charging is Level 2 charging. Therefore, if the governments indiscriminately push ahead with the establishment of public fast chargers in the current state, it can have a small effect on nurturing the EVs compared to the investment amount.

The diversity of the EV models also showed no significant impact on the annual sales of the EVs. This is presumed to be due to the lack of EVs in the large sedan segment favored by Korean consumers. For this reason, it would be beneficial for automakers to construct the EVs line-up after they carefully examine the consumers' needs on EVs.The implications drawn from this study are as follows. Firstly, it would be necessary to reconsider whether the policy instruments for the EV diffusion are demand-pull centered more than necessary. Of course, it is indispensable to lower the hurdles for the purchase and use of the EVs in order to create the initial market and reach the critical mass. However, the policy can be effective only if technological innovation occurs at an acceptable level for consumers. The evidence from the result informs that the driving range has a much higher impact on EV diffusion than the subsidies and tax exemption. Therefore, to find a fine balance between the demand-pull and technology-push policies would, in turn, improve the efficiency of the instruments.

Secondly, charging infrastructures are essential in the utilization of the EVs, but to solve the problem with it also could be overcome by technological innovation. Frequent charging itself means that the battery capacity does not meet the consumer's requirements, and the longer that is needed to 
charge the EV means that there is room for the further improvement of technologies around charging. When the battery capacity of the EV is large enough to drive a long distance, and the time needed to 'refill' the battery is not much different from that of the ICEVs, then the charging infrastructures would not hinder the widespread adoption of EVs.

This study has some limitations on data due to the emerging market characteristics of the EVs and a relatively short history of the policy implementation in Korea. A more accurate form of analysis is likely to be available when more comprehensive and extended time-series data is obtained in the near future. However, the authors would like to identify that the dataset used in this form of research is one of the best options so far.

Author Contributions: E.K. came up with the research ideas, constructed the dataset, conducted panel data analysis and wrote the paper. E.H. elaborated on the research ideas and reviewed the paper.

Funding: This research received no external funding.

Conflicts of Interest: The authors declare no conflict of interest.

\section{Appendix A}

Table A1. Descriptive statistics of explanatory variables.

\begin{tabular}{cccccc}
\hline Variables & Observations & Mean & $\begin{array}{c}\text { Standard } \\
\text { Deviation }\end{array}$ & Min & Max \\
\hline Diversity (units) & 80 & 6 & 1.684 & 3 & 8 \\
Range (km) & 80 & 136 & 16.730 & 120 & 168 \\
Price (10 thousand KRW) & 80 & 2343.4 & 113.149 & 2175 & 2501 \\
Income (10 thousand KRW) & 80 & 2914.675 & 712.139 & 2073 & 5221 \\
Subsidy (10 thousand KRW) & 80 & 2435.875 & 318.738 & 1949 & 3369 \\
Fast chargers (units per EV registered) & 80 & 0.168 & 0.159 & 0.01 & 0.79 \\
Fuel cost savings (10 thousand KRW) & 80 & 398.913 & 87.950 & 242 & 521 \\
\hline
\end{tabular}

Table A2. The conditional mean and conditional variance of annual sales of the EVs.

\begin{tabular}{cccc}
\hline Region & Mean & Variance & Observations \\
\hline Seoul & 1112.2 & $2,822,193$ & 5 \\
Busan & 146.4 & $25,727.3$ & 5 \\
Daegu & 400.6 & $529,008.3$ & 5 \\
Incheon & 69.4 & $12,019.3$ & 5 \\
Gwangju & 121.8 & $18,717.2$ & 5 \\
Daejeon & 54.4 & 8320.3 & 5 \\
Ulsan & 65.2 & 9673.7 & 5 \\
Gyeonggi & 354.6 & $330,406.8$ & 5 \\
Gangwon & 75.8 & $10,843.7$ & 5 \\
Chungbuk & 43.4 & 6370.8 & 5 \\
Chungnam & 58.2 & 4900.7 & 5 \\
Jeonbuk & 50.6 & 9410.8 & 5 \\
Jeonnam & 266.4 & $66,916.3$ & 5 \\
Gyeongbuk & 128.6 & $28,338.3$ & 5 \\
Gyeongnam & 157.4 & $14,405.3$ & 5 \\
Jeju & 1795.4 & $2,486,951$ & 5 \\
\hline Total & 306,275 & $539,703.6$ & 80 \\
\hline
\end{tabular}




\section{References}

1. Ministry of Trade, Industry, and Energy \& Korea Energy Agency. 2017 Energy Consumption Survey-Electric Vehicles Owners Survey Report; Korea Energy Agency: Yong-in, Korea, 2017.

2. Hardman, S.; Chandan, A.; Tal, G.; Turrentine, T. The effectiveness of financial purchase incentives for battery electric vehicles-A review of the evidence. Renew. Sustain. Energy Rev. 2017, 80, 1100-1111. [CrossRef]

3. She, Z.Y.; Sun, Q.; Ma, J.J.; Xie, B.C. What are the barriers to widespread adoption of battery electric vehicles? A survey of public perception in Tianjin, China. Transp. Policy 2017, 56, 29-40. [CrossRef]

4. Vassileva, I.; Campillo, J. Adoption barriers for electric vehicles: Experiences from early adopters in Sweden. Energy 2017, 120, 632-641. [CrossRef]

5. Mersky, A.C.; Sprei, F.; Samaras, C.; Qian, Z.S. Effectiveness of incentives on electric vehicle adoption in Norway. Transp. Res. Part D Transp. Environ. 2016, 46, 56-68. [CrossRef]

6. Sang, Y.N.; Bekhet, H.A. Modelling electric vehicle usage intentions: An empirical study in Malaysia. J. Clean. Prod. 2015, 92, 75-83. [CrossRef]

7. Zhang, Y.; Yu, Y.; Zou, B. Analyzing public awareness and acceptance of alternative fuel vehicles in China: The case of EV. Energy Policy 2011, 39, 7015-7024. [CrossRef]

8. Zhang, X.; Wang, K.; Hao, Y.; Fan, J.L.; Wei, Y.M. The impact of government policy on preference for NEVs: The evidence from China. Energy Policy 2013, 61, 382-393. [CrossRef]

9. Ministry of Environment Electric Vehicle Charging Stations Website. Available online: www.ev.or.kr (accessed on 5 November 2018).

10. International Energy Agency (IEA). Fuel Economy in Major Car Markets: Technology and Policy Drivers 2005-2017; IEA: Paris, France, 2019.

11. World Bank. Available online: https://data.worldbank.org/indicator/EN.POP.DNST (accessed on 2 November 2019).

12. Korea National Oil Corporation. Available online: http://www.opinet.co.kr/user/dopospdrg/dopOsPdrgSelect.do\# (accessed on 8 November 2019).

13. International Monetary Fund. Available online: http://data.imf.org/regular.aspx?key=61545850 (accessed on 8 November 2019).

14. Carley, S.; Krause, R.M.; Lane, B.W.; Graham, J.D. Intent to purchase a plug-in electric vehicle: A survey of early impressions in large US cites. Transp. Res. Part D Transp. Environ. 2013, 18, 39-45. [CrossRef]

15. Junquera, B.; Moreno, B.; Álvarez, R. Analyzing consumer attitudes towards electric vehicle purchasing intentions in Spain: Technological limitations and vehicle confidence. Technol. Forecast. Soc. Chang. 2016, 109, 6-14. [CrossRef]

16. Wang, S.; Li, J.; Zhao, D. The impact of policy measures on consumer intention to adopt electric vehicles: Evidence from China. Transp. Res. Part A Policy Pract. 2017, 105, 14-26. [CrossRef]

17. Plötz, P.; Schneider, U.; Globisch, J.; Dütschke, E. Who will buy electric vehicles? Identifying early adopters in Germany. Transp. Res. Part A Policy Pract. 2014, 67, 96-109. [CrossRef]

18. Hardman, S.; Shiu, E.; Steinberger-Wilckens, R. Comparing high-end and low-end early adopters of battery electric vehicles. Transp. Res. Part A Policy Pract. 2016, 88, 40-57. [CrossRef]

19. Kollmuss, A.; Agyeman, J. Mind the gap: Why do people act environmentally and what are the barriers to pro-environmental behavior? Environ. Educ. Res. 2002, 8, 239-260. [CrossRef]

20. Lane, B.; Potter, S. The adoption of cleaner vehicles in the UK: Exploring the consumer attitude-action gap. J. Clean. Prod. 2007, 15, 1085-1092. [CrossRef]

21. HanKook Economy. Available online: https://www.hankyung.com/economy/article/201904266805g (accessed on 2 November 2019). (In Korean).

22. Ministry of Land, Infrastructure and Transport. Available online: http://stat.molit.go.kr/portal/cate/ statFileView.do?hRsId=58\&hFormId=5 (accessed on 2 November 2019).

23. Brownstone, D.; Bunch, D.S.; Train, K. Joint mixed logit models of stated and revealed preferences for alternative-fuel vehicles. Transp. Res. Part B Methodol. 2000, 34, 315-338. [CrossRef]

24. Hidrue, M.K.; Parsons, G.R.; Kempton, W.; Gardner, M.P. Willingness to pay for electric vehicles and their attributes. Resour. Energy Econ. 2011, 33, 686-705. [CrossRef]

25. Egbue, O.; Long, S. Barriers to widespread adoption of electric vehicles: An analysis of consumer attitudes and perceptions. Energy Policy 2012, 48, 717-729. [CrossRef] 
26. Lane, B.W.; Dumortier, J.; Carley, S.; Siddiki, S.; Clark-Sutton, K.; Graham, J.D. All plug-in electric vehicles are not the same: Predictors of preference for a plug-in hybrid versus a battery-electric vehicle. Transp. Res. Part D Transp. Environ. 2018, 65, 1-13. [CrossRef]

27. Wang, S.; Wang, J.; Li, J.; Wang, J.; Liang, L. Policy implications for promoting the adoption of electric vehicles: Do consumer's knowledge, perceived risk and financial incentive policy matter? Transp. Res. Part A Policy Pract. 2018, 117, 58-69. [CrossRef]

28. Bjerkan, K.Y.; Nørbech, T.E.; Nordtømme, M.E. Incentives for promoting battery electric vehicle (BEV) adoption in Norway. Transp. Res. Part D Transp. Environ. 2016, 43, 169-180. [CrossRef]

29. Langbroek, J.H.; Franklin, J.P.; Susilo, Y.O. The effect of policy incentives on electric vehicle adoption. Energy Policy 2016, 94, 94-103. [CrossRef]

30. Hoen, A.; Koetse, M.J. A choice experiment on alternative fuel vehicle preferences of private car owners in the Netherlands. Transp. Res. Part A Policy Pract. 2014, 61, 199-215. [CrossRef]

31. Schuitema, G.; Anable, J.; Skippon, S.; Kinnear, N. The role of instrumental, hedonic and symbolic attributes in the intention to adopt electric vehicles. Transp. Res. Part A Policy Pract. 2013, 48, 39-49. [CrossRef]

32. Lieven, T. Policy measures to promote electric mobility-A global perspective. Transp. Res. Part A Policy Pract. 2015, 82, 78-93. [CrossRef]

33. Sierzchula, W.; Bakker, S.; Maat, K.; Van Wee, B. The influence of financial incentives and other socio-economic factors on electric vehicle adoption. Energy Policy 2014, 68, 183-194. [CrossRef]

34. Kim, S.; Lee, J.; Lee, C. Does driving range of electric vehicles influence electric vehicle adoption? Sustainability 2017, 9, 1783. [CrossRef]

35. Wang, N.; Tang, L.; Pan, H. A global comparison and assessment of incentive policy on electric vehicle promotion. Sustain. Cities Soc. 2019, 44, 597-603. [CrossRef]

36. Wee, S.; Coffman, M.; La Croix, S. Do electric vehicle incentives matter? Evidence from the 50 US states. Res. Policy 2018, 47, 1601-1610. [CrossRef]

37. Kwon, Y.; Son, S.; Jang, K. Evaluation of incentive policies for electric vehicles: An experimental study on Jeju Island. Transp. Res. Part A Policy Pract. 2018, 116, 404-412. [CrossRef]

38. Byun, H.; Shin, J.; Lee, C.Y. Using a discrete choice experiment to predict the penetration possibility of environmentally friendly vehicles. Energy 2018, 144, 312-321. [CrossRef]

39. Kim, M.K.; Oh, J.; Park, J.H.; Joo, C. Perceived value and adoption intention for electric vehicles in Korea: Moderating effects of environmental traits and government supports. Energy 2018, 159, 799-809. [CrossRef]

40. Jensen, A.F.; Cherchi, E.; Mabit, S.L. On the stability of preferences and attitudes before and after experiencing an electric vehicle. Transp. Res. Part D Transp. Environ. 2013, 25, 24-32. [CrossRef]

41. Helveston, J.P.; Liu, Y.; Feit, E.M.; Fuchs, E.; Klampfl, E.; Michalek, J.J. Will subsidies drive electric vehicle adoption? Measuring consumer preferences in the US and China. Transp. Res. Part A Policy Pract. 2015, 73, 96-112. [CrossRef]

42. Turrentine, T.S.; Kurani, K.S. Car buyers and fuel economy? Energy Policy 2007, 35, 1213-1223. [CrossRef]

43. Krupa, J.S.; Rizzo, D.M.; Eppstein, M.J.; Lanute, D.B.; Gaalema, D.E.; Lakkaraju, K.; Warrender, C.E. Analysis of a consumer survey on plug-in hybrid electric vehicles. Transp. Res. Part A Policy Pract. 2014, 64, 14-31. [CrossRef]

44. Christensen, L.; Kveiborg, O.; Mabit, S.L. The Market for electric vehicles-What do potential users want. In Proceedings of the 12th World Conference on Transportation Research, Lisbon, Portugal, 11-15 July 2010.

45. Higgins, C.D.; Mohamed, M.; Ferguson, M.R. Size matters: How vehicle body type affects consumer preferences for electric vehicles. Transp. Res. Part A Policy Pract. 2017, 100, 182-201. [CrossRef]

46. Heffner, R.R.; Kurani, K.S.; Turrentine, T.S. Symbolism in California's early market for hybrid electric vehicles. Transp. Res. Part D Transp. Environ. 2007, 12, 396-413. [CrossRef]

47. Sovacool, B.K.; Hirsh, R.F. Beyond batteries: An examination of the benefits and barriers to plug-in hybrid electric vehicles (PHEVs) and a vehicle-to-grid (V2G) transition. Energy Policy 2009, 37, 1095-1103. [CrossRef]

48. Johnstone, N.; Haščič, I.; Popp, D. Renewable energy policies and technological innovation: Evidence based on patent counts. Environ. Resour. Econ. 2010, 45, 133-155. [CrossRef]

49. Needell, Z.A.; McNerney, J.; Chang, M.T.; Trancik, J.E. Potential for widespread electrification of personal vehicle travel in the United States. Nat. Energy 2016, 1, 16112. [CrossRef]

50. Melliger, M.A.; Van Vliet, O.P.; Liimatainen, H. Anxiety vs reality-Sufficiency of battery electric vehicle range in Switzerland and Finland. Transp. Res. Part D Transp. Environ. 2018, 65, 101-115. [CrossRef] 
51. Shi, X.; Pan, J.; Wang, H.; Cai, H. Battery electric vehicles: What is the minimum range required? Energy 2019, 166, 352-358. [CrossRef]

52. Cherif, R.; Hasanov, F.; Pande, A. Riding the Energy Transition: Oil Beyond 2040; International Monetary Fund: Washington, DC, USA, 2017.

53. Figenbaum, E.; Assum, T.; Kolbenstvedt, M. Electromobility in Norway: Experiences and opportunities. Res. Transp. Econ. 2015, 50, 29-38. [CrossRef]

(C) 2019 by the authors. Licensee MDPI, Basel, Switzerland. This article is an open access article distributed under the terms and conditions of the Creative Commons Attribution (CC BY) license (http://creativecommons.org/licenses/by/4.0/). 